Abstract PS-138 Table 2 Logistic regression model adjusted for age, sex, race, PRISM 3 and inotrope use outcome: mortality predictor: day 3 fluid balance $(100 \mathrm{~mL} / \mathrm{kg})$

\begin{tabular}{lllll}
\hline & $\mathbf{n}$ & OR & $95 \% \mathrm{CI}$ & $\mathbf{p}$ \\
\hline All Patients & 209 & 1.64 & $1.14-2.37$ & 0.008 \\
Patients Without AKI & 153 & 1.35 & $0.68-2.7$ & 0.394 \\
Patients With AKI & 56 & 1.89 & $1.08-3.31$ & 0.027 \\
\hline
\end{tabular}

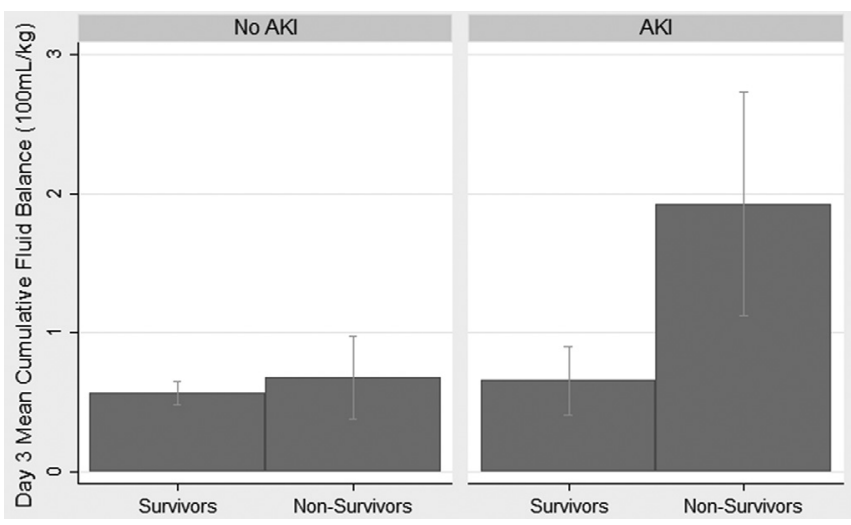

Abstract PS-138 Figure

Methods We calculated cumulative fluid balance 3 days after ARDS onset in a multi-centre cohort. AKI was defined as 'Injury' or 'Failure' by pRIFLE criteria (Akcan-Arikan 2007).

Results Patient characteristics are shown in Table 1. Mortality was higher in patients with AKI.

Fluid balance was associated with mortality independent of sex, age, race, PRISM 3 and vasopressor use; upon stratification, this association was to limited patients with AKI (Table 2 and Figure).

Conclusions Day 3 cumulative fluid balance and AKI are associated with mortality. The association with fluid balance is limited to patients with AKI. This has important implications for fluid management in ARDS patients.

\section{PS-139 NEURODEVELOPMENT WITHIN THE FIRST TWO YEARS AFTER IMPLEMENTATION OF THE EUROCONSORTIUM NEONATAL TREATMENT PROTOCOL IN CONGENITAL DIAPHRAGMATIC HERNIA PATIENTS: A MULTICENTER STUDY}

${ }^{1} \mathrm{KG}$ Snoek, ${ }^{2} \mathrm{C}$ Capolupo, ${ }^{2} \mathrm{~L}$ Aite, ${ }^{2} \mathrm{~A}$ Braguglia, ${ }^{1} \mathrm{RMH}$ Wijnen, ${ }^{2} \mathrm{~L}$ Valfrè, ${ }^{1} \mathrm{D}$ Tibboel, ${ }^{1} \mathrm{H}$ IJsselstijn. ${ }^{1}$ Department of Intensive Care and Paediatric Surgery, Erasmus MC Sophia Children's Hospital, Rotterdam, Netherlands; 'Department of Medical and Surgical Neonatology, Bambino Gesu Children's Hospital, Rome, Italy

\subsection{6/archdischild-2014-307384.435}

Background Since mortality in congenital diaphragmatic hernia $(\mathrm{CDH})$ is decreasing, morbidity such as neurodevelopmental delay receives increased attention. We evaluated neurodevelopmental outcome in high-risk $\mathrm{CDH}$ patients treated according to the Euroconsortium standardised neonatal treatment protocol (Reiss, 2010).

Methods Observational, prospective cohort study in $\mathrm{CDH}$ patients treated in two level-III university hospitals (Rotterdam (ECMO available) and Rome (no ECMO available)) between January 2009-April 2011. Sixty-three patients underwent standardised neurodevelopmental assessment at corrected age of 12

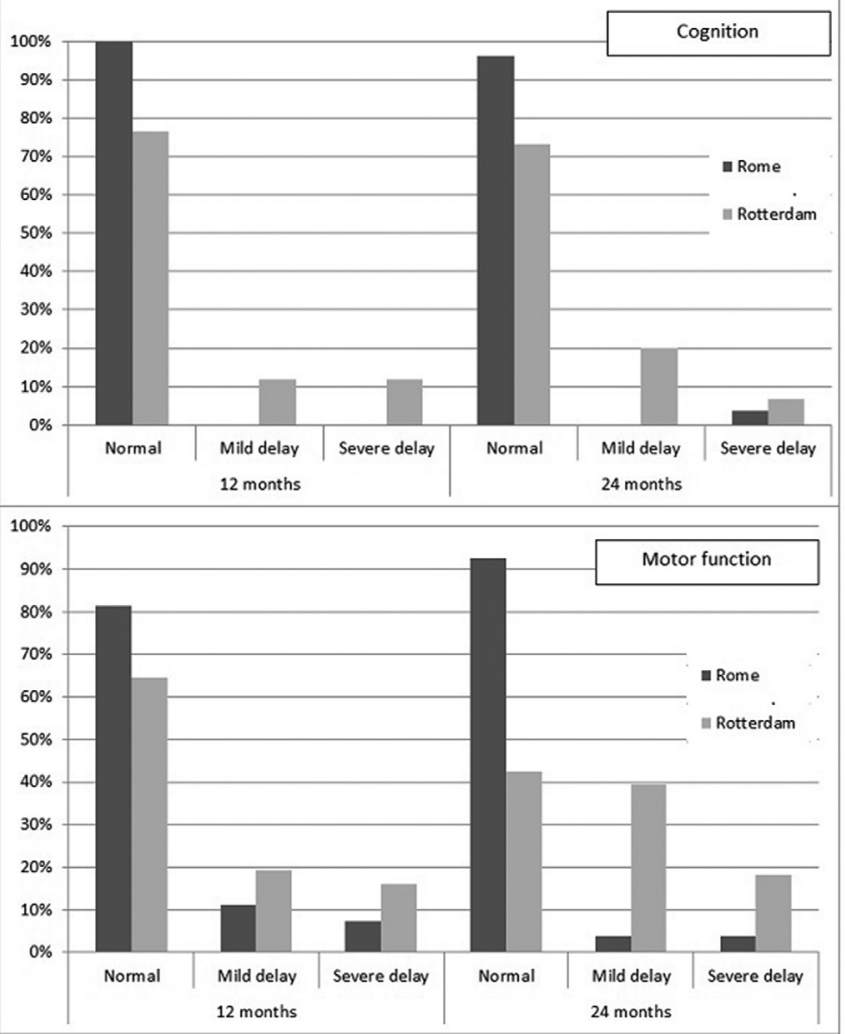

Abstract PS-139 Figure 1

and 24 months by using Bayley Scales of Infant Development (BSID)-II-NL (Rotterdam; Dutch reference data) or BSID-III (Rome; US reference data). Both centres were analysed separately due to differences in assessment instruments. Results are presented as $\mathrm{n}(\%)$, mean (SD) or median (range).

Results Mortality was $24.1 \%$ and $20.5 \%$ in Rotterdam and Rome, respectively. Baseline characteristics were for Rotterdam ( $\mathrm{n}=36) /$ Rome $(\mathrm{n}=27)$ : observed to expected lung-to-head ratio $53.8 \%(19.1) / 55.4 \%(15.8), \mathrm{p}=0.67$; SNAP-II score $(19$ $(0-40) / 7(0-25), \mathrm{p}<0.001$; chronic lung disease (i.e. oxygen dependency at day 28) in $15(41.7 \%) / 4(14.8 \%), p=0.14$; length hospital stay $21(6-387) / 27(15-82)$ days, $p=0.06$. In Rotterdam four patients $(11.1 \%)$ underwent ECMO treatment. Neurodevelopmental outcome is shown in Figure.

Conclusions At two years, the majority of $\mathrm{CDH}$ patients have normal cognition, but they are at risk for motor function delay. Future multicenter collaboration should focus on continuation of standardisation of treatment and follow-up to identify risk factors and reduce morbidity.

\section{PS-140 ¿SHOULD BE LOOK AT TIDAL VOLUMEN/WEIGHT VALUE AS A PREDICTIVE FACTOR FOR NON-INVASIVE VENTILATION FAILURE?}

${ }^{1} \mathrm{M}$ Pons-Odena, ${ }^{1} \mathrm{~L}$ Pérez Baena, ${ }^{1} \mathrm{~L}$ Rodriguez Guerinau, ${ }^{2} \mathrm{C}$ Pérez González, ${ }^{2}$ A Medina Villanueva, ${ }^{3}$ J López González, ${ }^{4} D$ Palanca Arias, ${ }^{3}$ J López-Herce, ${ }^{4} \mathrm{P}$ Garcia Iñiguez. 'PICU, Hospital Sant Joan de Déu, Barcelona, Spain: ${ }^{2} P I C U$, Hospital Universitario Central Asturias, Oviedo, Spain; ${ }^{3} P I C U$, Hospital Universitario Gregorio Marañón, Madrid, Spain; ${ }^{4}$ PICU, Hospital Universitario Miguel Servet, Zaragoza, Spain

\subsection{6/archdischild-2014-307384.436}

Background and aims Expected normal tidal volume values have not been described in children treated on NIV yet. Describe 
tidal volumen/weight $\left(\mathrm{V}_{\mathrm{T}} / \mathrm{W}\right)$ values according to the ventilators and interface used while receiving non-invasive ventilation (NIV) in the Paediatric Intensive Care Unit (PICU).

Methods Prospective study done in 4 Spanish PICU of University Hospitals during 2013. Consecutive register using a dataweb (www. NIVresearch.net), of patients diagnosed with acute respiratory failure $(\mathrm{ARF})$ treated with NIV. $\mathrm{V}_{\mathrm{T}} / \mathrm{W}$ was measured at the beginning of NIV, 1, 2, 6, 12 and 24 h. Failure was defined as need for intubation. Bonferroni's adjust for mean comparison was used.

Results 607 episodes were included. 58\% male. Median age was 11.3 months (P25 2.1-P75 60.5). Mean values $\mathrm{V}_{\mathrm{T}} / \mathrm{W}(\mathrm{ml} / \mathrm{kg})$ between groups success/failure were: starting NIV was $9.4 \pm 5$ DS vs $8.3 \pm 3.4 \mathrm{DS}$, at $1 \mathrm{~h} 8.5 \pm 4 \mathrm{DS}$ vs $7 \pm 3 \mathrm{DS}$ (p 0.02), at 2 h $9.2 \pm 5$ DS vs $7.8 \pm 6$ DS, at 6 h $9.7 \pm 5.4$ DS vs $8.5 \pm$ $3.8 \mathrm{DS}$, at $12 \mathrm{~h} 9 \pm 5 \mathrm{DS}$ vs $9.5 \pm 14 \mathrm{DS}$ and at $24 \mathrm{~h} 9 \pm 4,8 \mathrm{DS}$ vs $10.6 \pm 8 \mathrm{DS}$. Mean $\mathrm{V}_{\mathrm{T}} / \mathrm{W}$ shows significant differences between BiPAP Vision and conventional ventilator at start point (p 0.022), 1 h (p 0.01), 6 h (p 0.016), 12 h (p 0.01), 24 h (p 0.01 ). Differences of $\mathrm{V}_{\mathrm{T}}$ /weight between several types of interfaces reached statistical significance.

Conclusions $\mathrm{V}_{\mathrm{T}}$ /weight differs differs according to the ventilator and interface used. $\mathrm{V}_{\mathrm{T}}$ /weight differences between success and failure group suggest that this variable could be a new predictive factor for NIV failure. Further studies with multivariable adjustment should explore this hypothesis.

\section{PS-141 HAEMODYNAMIC EFFECTS OF NEURALLY ADJUSTED VENTILATORY ASSIST (NAVA) AFTER PAEDIATRIC CARDIAC SURGERY - A RANDOMISED CROSS-OVER STUDY}

${ }^{1} \mathrm{~F}$ Barriere, ${ }^{1} \mathrm{~N}$ Joram, ${ }^{1} \mathrm{~B}$ Gaillard-Leroux, ${ }^{1} \mathrm{P}$ Bourgoin, ${ }^{2} \mathrm{~A}$ Legrand, ${ }^{1} \mathrm{JM}$ Liet. ${ }^{1}$ Unité $d e$ Réanimation Pédiatrique, Hôpital Mère-Enfant CHU Nantes, Nantes, France, ${ }^{2} \mathrm{CIC}$ MèreEnfant, Hôpital Mère-Enfant CHU Nantes, Nantes, France

\subsection{6/archdischild-2014-307384.437}

Background and aims Neurally Adjusted Ventilatory Assist (NAVA) is an assist mode of mechanical ventilation that delivers an inspiratory pressure proportional to the electrical activity of the diaphragm. To date, no study has focused on its haemodynamic impact. The aim was to study haemodynamic effects of NAVA compared with conventional ventilation (CV).

Methods Prospective randomised cross-over study was conducted in a paediatric intensive care unit between June 2012 and March 2013. After a baseline period, infant received CV and NAVA during two consecutive periods of $30 \mathrm{~min}$ in a randomised order. During the last $10 \mathrm{~min}$ of each period, haemodynamic and respiratory parameters (including cardiac index assessed by transoesophageal Doppler ultrasonography) were collected.

Results Six infants (mean age $7.8 \pm 4.1$ months, mean weight $6.7 \pm 1.2 \mathrm{~kg}$ ) after cardiac surgery were enrolled. Results are expressed as percent variation in NAVA versus CV.

Conclusions After paediatric cardiac surgery, NAVA provides efficient ventilation with lower inspiratory pressures than $\mathrm{CV}$, and improves systolic blood pressure.

\section{PS-142 SAFETY OF EMPIRIC OUTPATIENT TREATMENT OF SUSPECTED TICK BORNE ILLNESS IN THE PAEDIATRIC EMERGENCY DEPARTMENT}

I Kane, D Arnold. Pediatric Emergency Medicine, Vanderbilt University School of Medicine, Nashville, USA

\subsection{6/archdischild-2014-307384.438}

Background/Aims Rocky Mountain spotted fever (RMSF) and human Ehrlichiosis are common tick-borne infections in the United States and many patients may be treated as outpatients with doxycycline. However, bacterial meningitis presents with similar symptoms. We evaluated whether empiric outpatient treatment for possible tick-borne illness resulted in cases of inadequately treated bacterial meningitis.

Methods We performed a review of all patients seen in our tertiary children's hospital emergency department (PED) from May to August of 2004-2013 who had a diagnosis consistent with possible tick-borne infection. Clinical and laboratory characteristics of all patients who returned to the PED within two weeks were collected from the electronic medical record.

Results 718 patients were discharged from the PED during our study period and $43(6.0 \%)$ returned to the PED within 2 weeks. There were no cases of bacterial meningitis and no deaths among patients who returned to the PED. 27/43 children (63\%) were discharged with doxycycline. 11/43 children (26\%) underwent lumbar puncture (LP) at their initial visit; $3 / 43$ patients (7.0\%), all of whom returned with neck pain, had an LP at their return visit and all three were diagnosed with viral meningitis. $16 / 43$ patients $(37 \%)$ were admitted after their second visit, with an average length of stay of 2.7 days.

Conclusion Empiric treatment of suspected tick-borne illness in our PED did not result in any cases of unrecognised bacterial meningitis. Further prospective studies may identify low risk children who may be discharged from the PED without extensive laboratory testing.

\section{PS-143 WITHDRAWN}

